\title{
Clinical value of delayed thallium-201 myocardial imaging in suspected acute myocardial infarction
}

\author{
J. H. MCKILlOP, J. G. TURNER, H. W. GRAY, R. G. BESSENT, AND W. R. \\ GREIG \\ From the University Department of Medicine and Department of Nuclear Medicine, Royal Infirmary, Glasgow, \\ and West of Scotland Health Boards, Department of Clinical Physics and Bio-Engineering, Glasgow
}

SUMMARY Fifty patients with acute chest pain had thallium-201 myocardial imaging performed three to six days after emergency admission to hospital. The image was abnormal in 20 out of 22 patients with acute transmural myocardial infarcts but in only 1 of 5 with acute subendocardial infarcts. Indistinguishable scan abnormalities caused by old infarcts were seen in 7 patients, and caused by myocardial ischaemia in 1 patient. A single thallium-201 myocardial scan some days after the onset of symptoms appears to be of little value in the clinical assessment of patients with suspected acute myocardial infarction.

In only approximately 50 per cent of patients admitted to hospital and later shown to have had an acute myocardial infarction can this diagnosis be made from the admission electrocardiogram (McGuinness et al., 1976) and in the remainder serial electrocardiograms and serum enzyme studies over the next few days are required. Even when these serial studies are complete, whether or not the patient has had an acute infarct will still sometimes remain in doubt. One proposed solution to this problem is the use of radionuclide myocardial imaging techniques (de Vernejoul et al., 1977).

Two approaches are possible. The first, so called 'positive' or 'hot spot' imaging, uses radiopharmaceuticals which accumulate preferentially in acutely infarcted myocardium, such as technetium-99m labelled phosphates (Perez, 1976), technetium-99 m labelled tetracycline (Holman et al., 1974), or technetium-99m labelled glucoheptonate (Rossman et al., 1975). Technetium-99m pyrophosphate is the most widely used of these compounds and is claimed to be a sensitive technique for the detection of acute myocardial infarcts, both transmural and subendocardial (Parkey et al., 1977), though a number of false positives have been recorded in patients with unstable angina (Willerson et al., 1975), stable angina (Mason et al., 1977), ventricular aneurysms (Ahmad et al., 1976), and in a variety of other situations, including after radiotherapy to the chest

Received for publication 18 October 1977 wall (Soin et al., 1977). The second approach, 'negative' or 'cold spot' imaging, uses radionuclides which accumulate in normal myocardium, notably radioactive potassium and its analogues. Of this group of agents the best presently available appears to be the heavy metal thallium (Nishiyama et al., 1976). Its radioisotope thallium-201 (T1 201), injected intravenously, is accumulated in left ventricular myocardium sufficiently to allow it to be imaged using the gamma camera (Bradley-Moore et al., 1975). The uptake of thallium-201 in different areas of the myocardium reflects regoinal myocardial blood flow, areas of decreased perfusion accumulating less thallium-201 and so appearing as 'cold spots' on the myocardial image (Strauss et al., 1975).

A thallium-201 myocardial image obtained within 6 hours of the onset of symptoms will be abnormal in 100 per cent of patients with acute myocardial infarction but the sensitivity of the technique decreases if delayed longer than this (Wackers et al., 1976). In many patients with acute infarction admission is delayed longer than 6 hours ( $\mathrm{McNeilly}$ and Pemberton, 1968). Even in those admitted within this period, early imaging is feasible only if the hospital has a gamma camera in the coronary care unit or has a mobile gamma camera, conditions not fulfilled by most hospitals in the United Kingdom.

The purpose of the present study was to assess the clinical value of thallium-201 myocardial imaging performed some days after the patient's admission with acute chest pain, when the patient 
was considered fit to be moved to the nuclear medicine department.

\section{Patients and methods}

Fifty patients (aged 27 to 76 years) were studied 3 to 6 days after admission to hospital with severe acute chest pain. The timing of the study was determined partly by when the clinician in charge of the patient considered them fit to be moved and partly by the availability of the radionuclide.

Two millicuries of thallous chloride ( $\mathrm{Tl} 201$ ), supplied by Duphar Laboratories Ltd, were injected intravenously at rest. Imaging was begun 5 to 10 minutes later using an Ohio-Nuclear Series 100 Gamma Camera fitted with a low energy, high resolution, parallel hole collimator and interfaced to a Varian $620 \mathrm{~L} / 100$ computer. The main contribution to the scintigraphic image is from those parts of the myocardium perpendicular to the front of the gamma camera (Wackers and de Jong, 1976), and multiple views are thus necessary to study all of the left ventricular myocardium. Anterior, $30^{\circ}$ left anterior oblique, $60^{\circ}$ left anterior oblique, and left lateral views were obtained with a minimum of 300000 counts in each view. Each complete study took 25 to 35 minutes. The images were recorded on black and white Polaroid prints and also stored on magnetic tape for later computer processing. The magnetic tape images were displayed on a colour television using a 14-point colour scale for different activity levels. Examples of Polaroid prints from a normal and an abnormal study are shown in Fig. 1.

All patients had electrocardiograms and serum enzyme estimations (creatine kinase, lactic dehydrogenase, aspartate aminotransferase, and alanine transferase) performed on each of the first 3 days after admission. In patients in whom electrocardiograph and enzyme studies did not establish the diagnosis other investigations, such as isotope lung scans, gastrointestinal radiology, and virological studies, were performed as indicated clinically.

The myocardial images were interpreted by two physicians who were unaware of the clinical details and the results of other investigations. In scans thought to show focal defects on visual inspection, quantification of the defect was attempted. Using the computer, regions of interest were drawn on the colour television image around the area of the suspected perfusion defect and also around myocardial areas which appeared normal. The activity per unit area for each region of interest was calculated and that in the abnormal area expressed as a percentage of that in the 'normal' area.
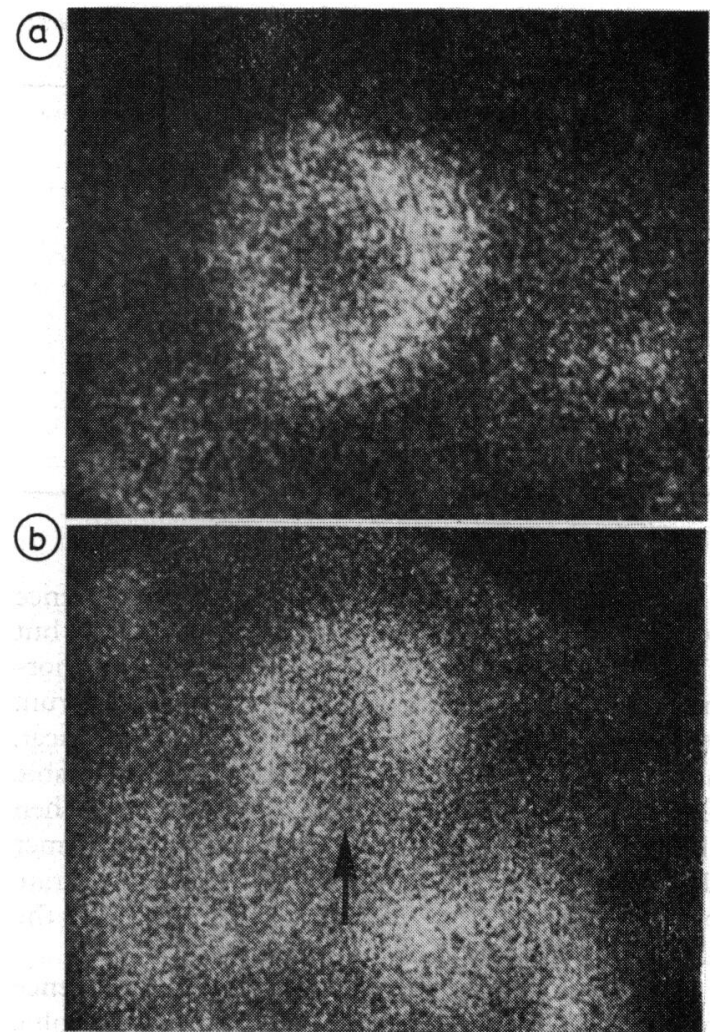

Fig. 1 Thallium-201 myocardial images $\left(30^{\circ} \mathrm{LAO}\right.$ views). (a) Normal scan: left ventricular wall appears as horseshoe shape of uniform activity. Central cold area corresponds to left ventricular cavity. (b) Abnormal scan: focal defect (indicated by arrow) caused by decreased uptake of radionuclide at the site of an acute inferior myocardial infarct.

\section{Results (Table)}

In 22 patients the electrocardiograms and serum enzyme studies suggested a diagnosis of acute transmural myocardial infarction. Of this group, $20 \mathrm{had}$ a focal area of decreased thallium uptake in the left ventricular myocardium, usually correlating well with the site of infarction indicated by electrocardiography. In 1 patient with an acute anterolateral transmural infarct and in 1 with a widespread anterior infarct (studied 4 and 6 days after admission respectively) the thallium studies were interpreted as normal.

In 5 patients the electrocardiogram and enzyme studies suggested a diagnosis of acute subendocardial myocardial infarction. In only one of this group was a focal defect seen on the thallium-201 myocardial images. 
Table Comparison of results of thallium-201 myocardial imaging and final clinical diagnoses

\begin{tabular}{lll}
\hline & $\begin{array}{l}\text { No. of } \\
\text { patients }\end{array}$ & $\begin{array}{l}\text { No. showing } \\
\text { focal scan } \\
\text { defect }\end{array}$ \\
\hline $\begin{array}{ll}\text { Acute transmural myocardial infarction } \\
\text { Acute subendocardial myocardial }\end{array}$ & 22 & 20 \\
infarction & 5 & 1 \\
Old transmural myocardial infarction & 9 & 7 \\
Myocardial ischaemia & 5 & 1 \\
$\begin{array}{l}\text { Miscellaneous } \\
\text { Pulmonary embolism }\end{array}$ & 4 & 1 \\
Pericarditis & 1 & 0 \\
Myocarditis & 1 & 0 \\
Intercostal myalgia & 1 & 0 \\
Hiatus hernia & 2 & 0 \\
\hline
\end{tabular}

Nine patients had electrocardiographic evidence of previous transmural myocardial infarction but showed no sequential electrocardiographic abnormalities of acute infarction and had normal serum enzymes. Seven of these patients showed focal scan abnormalities which were visually indistinguishable from those seen in the acute infarct patients. When the perfusion defects were quantified in the manner described above, it was still not possible to separate old infarcts from new infarcts on the basis of the thallium studies (Fig. 2).

Of 5 patients with electrocardiographic evidence of myocardial ischaemia but no electrocardiographic or enzyme evidence of acute or old myocardial infarction, 1 showed a focal scan defect.

Of the 50 patients, 9 had final diagnoses of a noncoronary nature; 8 had no focal scan defect, but in 1 patient with multiple pulmonary emboli and

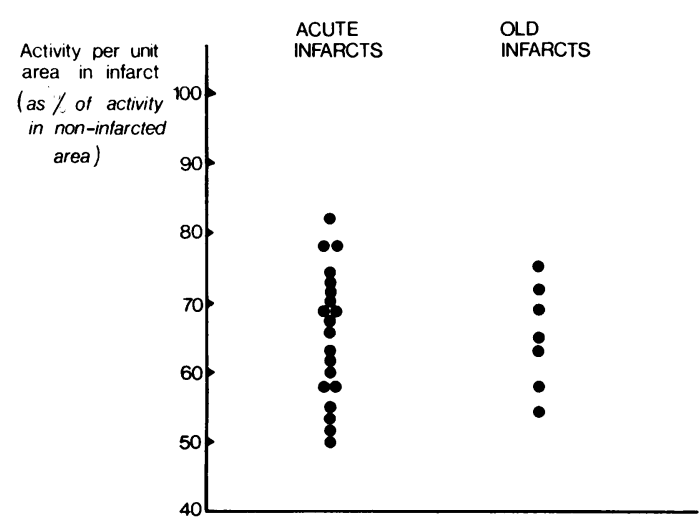

Fig. 2 Quantification of perfusion defect in 20 patients with abnormal scan resulting from acute transmural myocardial infarct and 7 patients with abnormal scan caused by previous transmural infarct. The two groups cannot be differentiated. acute cor pulmonale the thallium study showed an abnormality in the region of the interventricular septum, the significance of which is uncertain. It may represent an unrecognised myocardial infarction, though there was no clinical or other laboratory evidence to suggest this, or it may reflect the massive load placed acutely on the ventricular septum by the pulmonary hypertension.

In the series as a whole the sensitivity of the rest thallium scan in detecting the acute infarcts was 78 per cent while the specificity of a scan abnormality for diagnosing acute infarction was 61 per cent.

\section{Discussion}

It is concluded from the present study that thallium-201 myocardial imaging performed some days after the onset of symptoms is of very little clinical value in patients with suspected acute myocardial infarction. If imaging is delayed until this time a significant number of false negative studies occur, especially in patients with acute subendocardial infarction. If an abnormal image is obtained it is not possible, even after quantification, to say whether this represents acute myocardial infarction, old myocardial infarction, myocardial ischaemia, or a combination of these pathologies. In patients with electrocardiographic and serum enzyme evidence of acute myocardial infarction, delayed thallium-201 imaging is unlikely to give any additional information of clinical value, while in patients with equivocal or unhelpful electrocardiographic and enzyme studies the thallium-201 image cannot be relied on to indicate site or size of an acute infarct.

Thallium-201 myocardial imaging is a relatively expensive technique which shows great promise in the non-invasive assessment of patients with suspected, but stable, ischaemic heart disease, especially if the tracer is injected while the patient is exercising (Bailey et al., 1976). In the setting of suspected acute myocardial infarction a normal thallium-201 image obtained within 6 hours of the onset of symptoms effectively excludes this diagnosis (Wackers et al., 1976), though an abnormal image does not prove it. We suggest that if it cannot be performed during this very early period a single rest thallium-201 myocardial study has no place in the routine assessment of patients with suspected acute myocardial infarction. If a radionuclide technique is required for such patients, 'hot spot' infarct labelling is more likely to be useful.

\section{References}

Ahmad, M., Dubiel, J. P., Verdon, T. A., Jr., and Martin, 
R. H. (1976). Technetium 99m stannous pyrophosphate myocardial imaging in patients with and without left ventricular aneurysm. Circulation, 53, 833-838.

Bailey, I., Strauss, H. W., and Pitt, B. (1976). Thallium-201 myocardial perfusion imaging at rest and stress: sensitivity for detection of coronary artery disease (abstract). fournal of Nuclear Medicine, 17, 522.

Bradley-Moore, P. R., Lebowitz, E., Greene, M. W., Atkins, H. L., and Ansari, A. N. (1975). Thallium-201 for medical use. II. Biologic behaviour. Fournal of Nuclear Medicine, 16, 156-160.

de Vernejoul, P., Ducassou, D., Guiraud, R., Robert, J., Nouel, J-P., and Witz, H. (1977). Practical Atlas of Cardiac Scintigraphy. Kluwer Harrap Handbooks, London.

Holman, B. L., Lesch, M., Zweimann, F. G., Temte, J., Lown, B., and Gorlin, R. (1974). Detection and sizing of acute myocardial infarcts with ${ }^{99 \mathrm{~m}} \mathrm{Tc}$ (Sn) tetracycline. New England fournal of Medicine, 291, 159-163.

McGuinness, J. B., Begg, T. B., and Semple, T. (1976). The first electrocardiogram in recent myocardial infarction. British Medical fournal, 2, 449-451.

McNeilly, R. H., and Pemberton, J. (1968). Duration of last attack in 998 fatal cases of coronary artery disease and its relation to possible cardiac resuscitation. British Medical Fournal, 3, 139-142.

Mason, J. W., Myers, R. W., Alderman, E. L., Stinson, E. B., Goris, M. L., and Kriss, J. P. (1977). Technetium-99m pyrophosphate myocardial uptake in patients with stable angina pectoris. American fournal of Cardiology, 40, 1-5.

Nishiyama, H., Sodd, V. J., Adolph, R. J., Saenger, E. L., Lewis, J. T., and Gabel, M. (1976). Intercomparison of myocardial imaging agents: ${ }^{201} \mathrm{Tl},{ }^{129} \mathrm{Cs},{ }^{43} \mathrm{~K}$ and ${ }^{81} \mathrm{Rb}$. Fournal of Nuclear Medicine, 17, 880-889.

Parkey, R. W., Bonte, F. J., Buja, M., Stokeley, E. M., and
Willerson, J. T. (1977). Myocardial infarct imaging with technetium-99m phosphate. Seminars in Nuclear Medicine, 7, 15-28.

Perez, L. (1976). Clinical experience: technetium-99m labelled phosphates in myocardial imaging. Clinical Nuclear Medicine, 1, 2-9.

Rossman, D. J., Rouleau, J., Strauss, H. W., and Pitt, B. (1975). Detection and size estimation of acute myocardial infarction using ${ }^{99 \mathrm{~m}} \mathrm{Tc}$-glucoheptonate. Fournal of Nuclear Medicine, 16, 980-985.

Soin, J. S., Cox, J. D., Youker, J. E., and Swartz, H. M. (1977). Cardiac localization of $99 \mathrm{mTc}$-(Sn)-pyrophosphate following irradiation of the chest. Radiology, 124, 165-168.

Strauss, H. W., Harrison, K., Langan, J. K., Lebowitz, E., and Pitt, B. (1975). Thallium-201 for myocardial imaging. Relation of Thallium-201 to regional myocardial perfusion. Circulation, 51, 641-645.

Wackers, F. J. Th., and de Jong, R. B. J. (1976). Myocardial imaging with Thallium-201. Medica mundi, 21, 103-113.

Wackers, F. J. Th., Sokole, E. B., Samson, G., Shoot, J. B. v. d., Lie, K. I., Liem, K. L., and Willens, H. J. J. (1976). Value and limitations of thallium-201 scintigraphy in the acute phase of myocardial infarction. New England fournal of Medicine, 295, 1-5.

Willerson, J. T., Parkey, R. W., Bonte, F. J., Meyer, S. L., Atkins, J. M., and Stokely, E. M. (1975). Technetium stannous pyrophosphate myocardial scintigrams in patients with chest pain of varying etiology. Circulation, 51, 10461052.

Requests for reprints to $\mathrm{Dr}$ J. H. McKillop, University Department of Medicine, Royal Infirmary, Glasgow G4 0SF. 